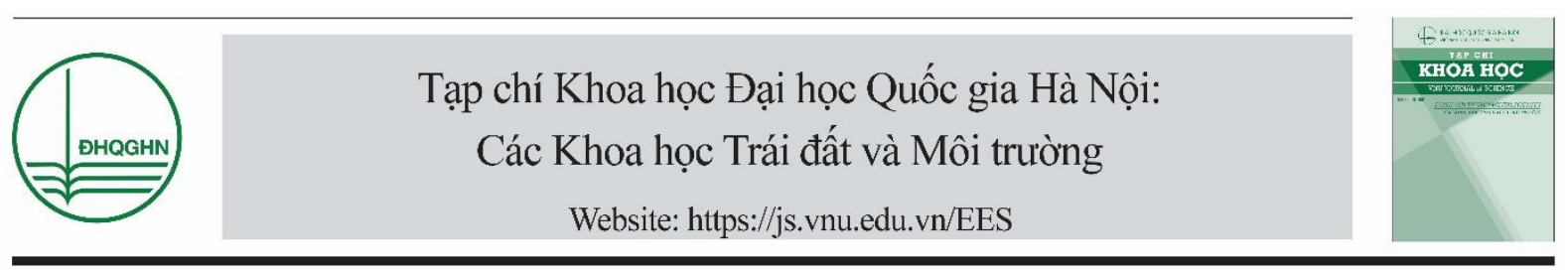

\title{
Đánh giá sự tích lũy và rủi ro sinh thái một số kim loại nặng trong trầm tích mặt khu vực hạ lưu sông Đáy
}

\author{
Lê Thị Trinh, Kiều Thị Thu Trang, Nguyễn Thành Trung, \\ Nguyễn Khánh Linh, Trịnh Thị Thắm* \\ Truờng Đại học Tài nguyên và Môi truoòng Hà Nội, \\ 41A Phú Diễn, Cầu Diễn, Hà Nội, Việt Nam \\ Nhận ngày 13 tháng 12 năm 2018 \\ Chỉnh sửa ngày 20 tháng 12 năm 2018; Chấp nhận đăng ngày 21 tháng 12 năm 2018
}

\begin{abstract}
Tóm tắt: Hệ thống lưu vực sông Nhuệ - Đáy đang chịu sự gia tăng về số lượng và lưu lượng nước thải từ các hoạt động sản xuất, sinh hoạt. Các nguồn thải mang theo các chất hữu cơ, kim loại nặng, vi sinh vật,... tích lũy trong trầm tích và hệ sinh thái dưới nước gây ảnh hưởng đến môi trường nước và hệ sinh thái. Trong nghiên cứu này, sự tích lũy kim loại nặng trong trầm tích tại khu vực hạ lưu sông Đáy được đánh giá thông qua chỉ số rủi ro sinh thái tiềm năng của một số kim loại trong trầm tích. Kêt quả nghiên cứu cho thấy, trong 22 mẫu trầm tích tại khu vực hạ lưu sông Đáy đều phát hiện sự có mặt của các kim loại $\mathrm{Cu}, \mathrm{Pb}, \mathrm{Cd}, \mathrm{Cr}$ với hàm lượng dao động trong khoảng tương ứng là $15,8 \div 82,6 ; 13,1 \div 72,1 ; 0,189 \div 2,43 ; 16,1 \div 97,3 \mathrm{mg} / \mathrm{kg}$ trọng lượng khô. Chỉ số rủi ro sinh thái tiềm năng của các kim loại nằm trong khoảng từ 11,4 đến 78,7 nên khu vực nghiên cứu có mức độ rủi ro kim loại thấp. Số liệu này có thể làm rõ mức độ rủi ro tiềm năng của khu vực và là cơ sở khoa học của các biện pháp kiểm soát và giảm thiểu các nguồn gây ô nhiễm môi trường từ các hoạt động kinh tế xã hội của lưu vực sông Nhuệ - Đáy.
\end{abstract}

Từ khoá: Kim loại nặng, trầm tích, rủi ro sinh thái, hạ lưu sông Đáy

\section{Mở đầu}

Sông Đáy là một chi lưu nằm bên hữu ngạn của sông Hồng (từ $20^{0} 33^{\prime}$ đến $21^{\circ} 19^{\prime}$ vĩ độ Bắc và $105^{\circ} 17^{\prime}$ đến $105^{0} 50^{\prime}$ kinh độ Đông), chiều dài sông chính khoảng $247 \mathrm{~km}$ (tính từ cửa Hát Môn đến cửa Đáy trước khi đổ ra biển Đông), diện tích lưu vực khoảng $6.595 \mathrm{~km}^{2}$. Lưu vực được giới hạn bao bởi đê sông Hồng ở phía Bắc, phía Đông giáp với lưu vực sông Nhuệ, phía Tây giáp tỉnh Hòa Bình, phía Nam giáp tỉnh Hà Nam.

Sông Đáy lấy nguồn nước chính từ sông Hồng và chảy ra vịnh Bắc Bộ. Sông Đáy có lòng sông chảy gọn trong vùng đồng bằng Bắc Bộ với

\footnotetext{
*Tác giả liên hệ. ĐT.: 84-983307385.

Email: tttham@hunre.edu.vn

https://doi.org/10.25073/2588-1094/vnuees.4351
} 
dòng sông chảy song song bên hữu ngạn hạ lưu sông Hồng. Theo số liệu thống kê của Bộ Tài nguyên và Môi trường [1], hệ thống lưu vực sông Nhuệ - Đáy đang chịu sự gia tăng về số lượng và lưu lượng nguồn thải nước thải từ các hoạt động sản xuất, sinh hoạt. Tính đến tháng 10/2016, trên lưu vực sông Nhuệ - sông Đáy có 1.982 nguồn thải, trong đó có 1.662 nguồn thải từ cơ sở sản xuất, kinh doanh; 39 nguồn thải từ khu công nghiệp, cụm công nghiệp; 137 từ cơ sở y tế và 144 làng nghề. Thành phố Hà Nội là địa phương có tổng số nguồn thải cao nhất chiếm tới $60 \%$ trên toàn lưu vực. Trong khi đó số lượng nguồn thải tại các tỉnh Hà Nam, Nam Định, Hòa Bình và Ninh Bình cũng có chiều hướng gia tăng [1]. Các nguồn thải có khả năng gây ô nhiễm các chất hữu cơ, chất rắn, kim loại nặng, gây đục, nhiễm vi khuẩn và gây hiện tượng phú dưỡng cho môi trường sông Nhuệ - Đáy.

Nghiên cứu về kim loại nặng trong trầm tích với mục đích nhằm hiểu rõ các tác động của chúng đến hệ sinh thái dưới nước. Kim loại nặng là một trong những nhóm chất ô nhiễm môi trường quan trọng cần được nghiên cứu để đánh giá tác động của ô nhiễm môi trường đến sức khỏe con người và hệ sinh thái tự nhiên [2]. Trầm tích cũng là một thành phần cơ bản trong môi trường cung cấp thức ăn cho hệ sinh thái tự nhiên cũng như con người. Các chất ô nhiễm từ trầm tích cũng là nguồn phơi nhiễm quan trọng của hệ sinh thái dưới nước và con người.

Kim loại nặng trong môi trường nước tại nhiều khu vực trên thế giới thường có hàm lượng không cao nhưng đó là nguồn gốc của sự tích lũy và gia tăng nồng độ kim loại trong trầm tích, đặc biệt tại các khu vực cửa sông, ven biển. Nhiều nghiên cứu chỉ ra rằng kim loại nặng như đồng $(\mathrm{Cu})$, Chì $(\mathrm{Pb})$, Cadimi $(\mathrm{Cd})$ và $\mathrm{Crom}(\mathrm{Cr})$ trong môi trường nước, dất, sinh học là những kim loại rất cần thiết cho quá trình trao đổi chất của cơ thể sống, tuy nhiên nó sẽ gây độc ở một nồng độ nhất định. Nồng độ của các kim loại này phụ thuộc rất nhiều vào nguồn gốc phát sinh từ các hoạt động phát triển kinh tế xã hội [2]

Các rủi ro tiềm năng của kim loại nặng đối với hệ sinh thái tại khu vực nghiên cứu được đánh giá theo các hệ số: [3], [4]:
- Hệ số làm giàu trầm tích $(\mathrm{EF})$

- Chỉ số tích lũy địa chất (Igeo

- Chỉ số tải ô nhiễm (PLI)

- Chỉ số rủi ro sinh thái tiềm năng

Phương pháp chỉ số rủi ro sinh thái tiềm năng là một trong những phương pháp được xem xét trên cả hai yếu tố là nống độ của kim loại trong môi trường và hệ số đáp ứng độc học.

Mục đích của nghiên cứu này là đánh giá chỉ số rủi ro sinh thái tiềm năng của một số kim loại trong trầm tích khu vực hạ lưu sông đáy nhằm hiểu rõ mức độ rủi ro tiềm năng của khu vực. Kết quả nghiên cứu có thể là cơ sở khoa học của các biện pháp kiểm soát và giảm thiểu các nguồn gây ô nhiễm môi trường từ các hoạt động kinh tế xã hội của lưu vực sông Nhuệ - Đáy.

\section{Phương pháp nghiên cứu}

\subsection{Lấy mẫu và bảo quản mẫu}

Các vị trí lấy mẫu được lựa chọn trên cơ sở khảo sát thực tế dọc sông Đáy từ Hà Nam đến cửa Đáy và bản đồ địa giới khu vực nghiên cứu. Quá trình khảo sát cho thấy, sông Đáy chảy qua Hà Nam tiếp nhận các nguồn thải từ sản xuất sơn, xi măng, phân bón... Tại địa phận tỉnh Ninh Bình, các nguồn thải chủ yếu là sản xuất cơ khí, xi măng, phân bón, tại Nam Định là cơ khí đúc và thủ công mỹ nghệ. Theo đó, 5 vị trí lấy mẫu được chọn tại Hà Nam, 6 vị trí tại Ninh Bình, 6 vị trí tại Nam Định và 5 vị trí ven biển khu vực Cửa Đáy. Sử dụng phần mềm Mapinfo 15.0 để biểu thị bản đồ lấy mẫu trên cơ sở các tọa độ vị trí lấy mẫu thực tế. Hình 1 mô tả bản đồ vị trí lấy mẫu tại khu vực hạ lưu sông Đáy.

Mẫu được lấy bằng cuốc bùn Peterson để thu được lớp trầm tích mặt khoảng $5-10 \mathrm{~cm}$. Mẫu sau khi lấy được trộn đều, tiến hành chuyển vào bình thủy tinh tối màu và bảo quản trong hộp, làm lạnh bằng đá muối. Mẫu được di chuyển về phòng thí nghiệm theo TCVN 6663-15:2008 (ISO 5667-15:1999) [5]. 


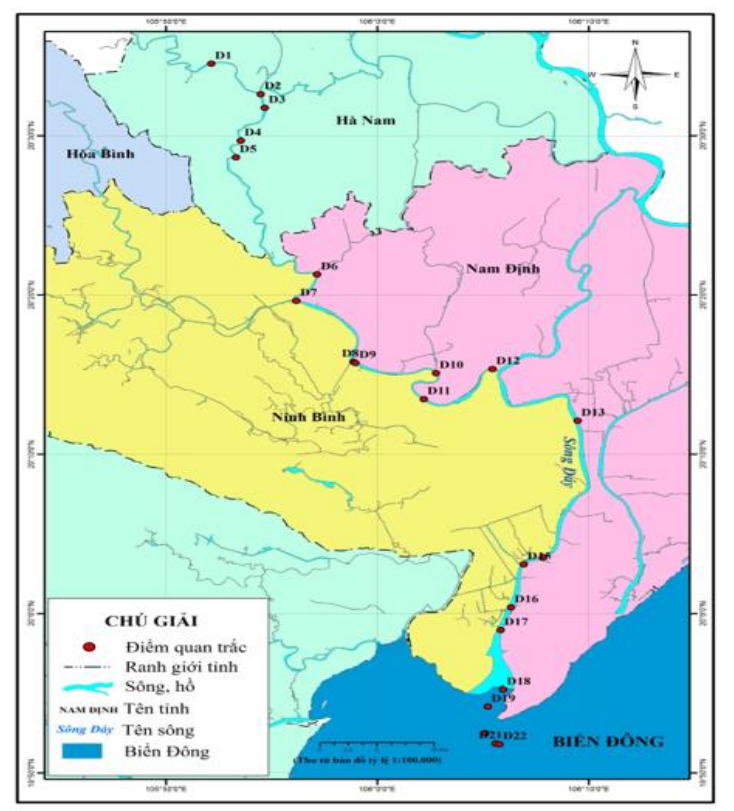

Hình 1. Bản đồ các vị trí lấy mẫu hạ lưu sông Đáy.

Mẫu trầm tích sau khi lấy về được phơi khô trong phòng tối và kín, sau đó mẫu được nghiền nhỏ, loại bỏ các thành phần tạp, rây qua rây có kích thước lỗ $0,63 \mu \mathrm{m}$ và thu mẫu có kích cỡ hạt $<0,63 \mu \mathrm{m}$ để phân tích hàm lượng kim loại trong pha trầm tích hoạt động nhất, chứa chủ yếu là các hạt sét và thịt [6]. Các mẫu được bảo quản trong tủ lạnh sâu chờ phân tích, trước khi phân tích mẫu được để ở nhiệt độ phòng và xác định hệ số khô kiệt theo TCVN 4080:2011[7].

\subsection{Xử lý và phân tích mẫu}

Quá trình xử lý mẫu để phân tích các kim loại $\mathrm{Cd}, \mathrm{Cr}, \mathrm{Cu}, \mathrm{Pb}$ được tiến hành theo hướng dần của EPA 3050B (1996) [8]. Quy trình xử lý mẫu được tóm tắt như sau: Cân chính xác khoảng $1 \mathrm{~g}$ trầm tích cho vào bình nón $250 \mathrm{ml}$, thêm chính xác $10,0 \mathrm{~mL}$ dung dịch $\mathrm{HNO}_{3}$ 1:1, đun hỗn hợp trên bếp cách cát ở $95^{\circ} \mathrm{C}$ trong 10 - 15 phút. Sau khi đun, để nguội hỗn hợp 5 phút, tiếp tục thêm chính xác $5,0 \mathrm{~mL}$ dung dịch $\mathrm{HNO}_{3}$ đặc, đun trên bếp cách cát trong khoảng 30 phút cho tới khi hết khí nâu thoát ra, rồi để nguội hỗn hợp đến nhiệt độ phòng. Thêm $2,0 \mathrm{~mL}$ nước cất hai lần và $3,0 \mathrm{~mL}$ dung dịch $\mathrm{H}_{2} \mathrm{O}_{2} 30 \%$ vào bình và đun đến khi giảm bọt khí, sau đó thêm chính xác $5,0 \mathrm{~mL}$ dung dịch $\mathrm{H}_{2} \mathrm{O}_{2} 30 \%$ và đun tiếp ở $95^{\circ} \mathrm{C}$ cho đến khi dung dịch còn khoảng $5 \mathrm{~mL}$ thì dừng đun. Để nguội hỗn hợp, loại bỏ cặn, chuyển toàn bộ phần dụng dịch vào bình định mức $50 \mathrm{~mL}$, định mức đến vạch bằng dung dịch $\mathrm{HNO}_{3} 2 \%$. Mẫu trầm tích sau khi xử lý được tiến hành đo trên thiết bị quang phổ hấp thụ nguyên tử ngọn lửa F-AAS - Thermo Fisher M6. Các mẫu được phân tích lặp theo ...

\subsection{Phưong pháp đánh giá rủi ro sinh thái}

Nghiên cứu này sử dụng chỉ số rủi ro sinh thái tiềm năng (RI) được đề xuất bởi Hakanson (1980) [4] để đánh giá nguy cơ sinh thái tiềm năng của kim loại nặng. Hệ số RI được xác định dựa trên 3 yếu tố cơ bản để đánh giá mức độ rủi ro: mức độ ô nhiễm $(\mathrm{Cd})$, mức độ độc tính của kim loại nặng $\left(T_{r}^{i}\right)$ và yếu tốrủi ro sinh thái của từng kim loại $\left(E_{r}^{i}\right)$. Theo phương pháp này, yếu tố rủi ro sinh thái thành phần của các kim loại, hệ số rủi ro sinh thái tổng cộngđược thực hiện theo cáo công thức sau đây:

$$
R I=\sum_{i=1}^{n} E_{r}^{i} \quad E_{r}^{i}=C_{f}^{i} \cdot T_{r}^{i} \quad C_{f}^{i}=\frac{C_{i}}{C_{n}^{i}}
$$

Trong đó:

$C_{i}$ : Hàm lượng KLN đo được trong trầm tích tại khu vực nghiên cứu $(\mathrm{mg} / \mathrm{kg})$

$\boldsymbol{C}_{\boldsymbol{f}}^{\boldsymbol{i}}$ : Yếu tố ô nhiễm của từng kim loại

$\boldsymbol{C}_{\boldsymbol{n}}^{\boldsymbol{i}}$ : Hàm lượng tham chiếu của KLN thời kỳ tiền công nghiệp

$\boldsymbol{E}_{\boldsymbol{r}}^{\boldsymbol{i}}$ : Yếu tố rủi ro sinh thái của từng $\mathrm{KLN}$

$\boldsymbol{T}_{r}^{\boldsymbol{i}}$ : Hệ số độc tính của KLN

Bảng 2. Mức độ rủi ro sinh thái của các KLN [4]

\begin{tabular}{lll}
\hline \multicolumn{1}{c}{$\boldsymbol{E}_{\boldsymbol{r}}^{\boldsymbol{i}}$} & $\mathrm{RI}$ & $\begin{array}{l}\text { Mức độ rủi ro } \\
\text { sinh thái của } \\
\text { KLN }\end{array}$ \\
\hline $\boldsymbol{E}_{r}^{\boldsymbol{i}}<40$ & $\mathrm{RI}<110$ & Thấp \\
$40 \leq E_{r}^{i}<80$ & $110 \leq \mathrm{RI}<220$ & Vừa phải \\
$80 \leq E_{r}^{i}<160$ & $220 \leq \mathrm{RI}<440$ & $\begin{array}{l}\text { Đáng quan } \\
\text { tâm }\end{array}$ \\
$160 \leq E_{r}^{i}<$ & $\mathrm{RI} \geq 440$ & i Ccao \\
320 & & Rất cao \\
$E_{r}^{i} \geq 320$ & &
\end{tabular}

(Nguồn: Hakanson và cộng sự 1980) 


\section{Kết quả và thảo luận}

\subsection{Mức độ tích lũy kim loại nặng trong trầm tích}

Kết quả hàm lượng một số kim loại nặng trong trầm tích khu vực hạ lưu sông Đáy được tóm tắt trong bảng 1 . Hàm lượng các kim loại $\mathrm{Pb}$, $\mathrm{Cu}, \mathrm{Cd}, \mathrm{Cr}$ trong mẫu trầm tích (22 mẫu) được so sánh với Quy chuẩn kĩ thuật quốc gia về Chất lượng trầm tích - QCVN 43:2012/BTNMT và Hướng dẫn chất lượng trầm tích tỉnh Ontario, Canada (1993) - các giá trị quy định để bảo vệ hệ thủy sinh nhằm đánh giá mức độ ô nhiễm cũng như tích lũy kim loại nặng tại khu vực nghiên cứu.

Bảng 1. Hàm lượng kim loại nặng trong mẫu trầm tích

Đonn vị: $m g / k g$ trọng luợng khô

\begin{tabular}{lllll}
\hline Sông Đáy $(\mathrm{n}=22)$ & $\mathrm{Pb}$ & $\mathrm{Cu}$ & $\mathrm{Cd}$ & $\mathrm{Cr}$ \\
\hline Nhỏ nhất & 15,8 & 13,1 & 0,189 & 16,1 \\
Lớn nhất & 82,6 & 72,1 & 2,43 & 97,3 \\
$\begin{array}{l}\mathrm{SD} \\
\begin{array}{l}\text { Giới hạn ảnh } \\
\text { hưởng a1 }\end{array}\end{array}$ & 21,4 & 16,1 & 0,50 & 21,1 \\
$\begin{array}{l}\text { Giới hạn ảnh } \\
\text { hương a }\end{array}$ & 112 & 108 & 4,2 & 160 \\
$\begin{array}{l}\text { Mức độ thấp nhất } \\
\text { có ảnh hưởng } \\
\text { Mức độ gây ảnh } \\
\text { hưởng nghiêm } \\
\text { trọng }\end{array}$ & 31 & 16 & 0,6 & 26 \\
\hline
\end{tabular}

$\mathrm{a}_{1}, \mathrm{a}_{2}$ : QCVN 43:2012/BTNMT - Quy chuẩn kỹ thuật Quốc gia về chất lượng trầm tích đối với trầm tích nước ngọt; đối với trầm tích nước mặn, lợ.

b: Hướng dẫn về chất lượng trầm tích tỉnh Ontario, Canada - các giá trị quy định để bảo vệ hệ thủy sinh.

Kết quả hàm lượng $\mathrm{Pb}$ trong mẫu trầm tích dao động từ $15,8 \mathrm{mg} / \mathrm{kg}$ (tại vị trí SD4) đến 82,6 $\mathrm{mg} / \mathrm{kg}$ trọng lượng khô (vị trí SD16). Kết quả phân tích hàm lượng chì ở tất cả các mẫu đều không vượt quá giá trị giới hạn của trầm tích nước ngọt $(91,3 \mathrm{mg} / \mathrm{kg}$ trọng lượng khô) và trầm tích nước mặn, nước lợ (112mg/kg trọng lượng khô) được quy định trong quy chuẩn chất lượng trầm tích QCVN 43: 2012/BTNMT. Theo hướng dẫn về chất lượng trầm tích tỉnh Ontario Canada các giá trị quy định để bảo vệ hệ thủy sinh, 12/22 vị trí có hàm lượng $\mathrm{Pb}$ vượt mức ảnh hường thấp (LEL) từ 1,06 (vị trí SD 11) đến 2,66 lần (vị trí SD16).

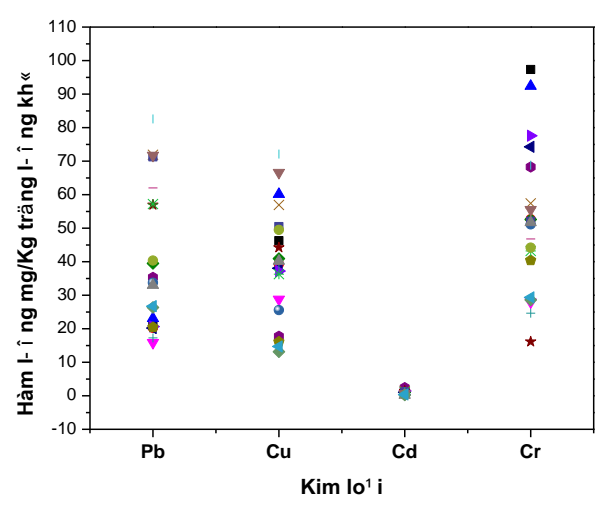

Hình 2. Hàm lượng kim loại nặng trong mẫu trầm tích khu vực nghiên cứu.

Kết quả hàm lượng kim loại ở bảng 1 cũng cho thấy hàm lượng $\mathrm{Cu}$ trong các mẫu trầm tích nằm trong khoảng từ $13,1 \mathrm{mg} / \mathrm{kg}$ đến $72,1 \mathrm{mg} / \mathrm{kg}$ trọng lượng khô. Hàm lượng của tất cả các mẫu đều nằm trong giới hạn của $\mathrm{QCVN}$ 43:2012/BTNMT đối với cả trầm tích nước ngọt và nước mặn, nước lợ. Tuy nhiên theo hướng dẫn chất lượng trầm tích tỉnh Ontario - Canada thì chỉ có duy nhất điểm $\mathrm{SD} 4$ có hàm lượng $\mathrm{Cu}$ nằm dưới mức ảnh hưởng thấp LEL, các mẫu còn lại đều vượt mức ảnh hưởng thấp từ 1,08 đến 5,2 lần.

Với khoảng giá trị hàm lượng từ 0,189 đến $2,43 \mathrm{mg} / \mathrm{kg}$ trọng lượng khô, kết quả phân tích kim loại $\mathrm{Cd}$ trong mẫu trầm tích tại tất cả các vị trí đều không vượt giá trị giới hạn được quy định trong QCVN 43:2012/BTNMT. Các vị trí lấy mẫu bên trong sông có hàm lượng $\mathrm{Cd}$ cao hơn nhiều so với các điểm ngoài cửa sông (trung bình từ 3- 4 lần). Theo hướng dẫn chất lượng trầm tích tỉnh Ontario - Canada, hàm lượng $\mathrm{Cd}$ tại khu vực nghiên cứu đều dưới mức SEL, trong khi với mức ảnh hưởng thấp LEL, các vị trí lấy mẫu trong sông đều vượt từ 1,2 đến 4,0 lần, cao nhất ở vị trí SD8 đạt giá trị $2,43 \mathrm{mg} / \mathrm{kg}$ trọng lượng khô. 
Hàm lượng Cr trong các mẫu trầm tích dao động từ 16,1 đến $97,3 \mathrm{mg} / \mathrm{kg}$ trọng lượng khô. Theo quy chuẩn chất lượng trầm tích QCVN 43: 2012/BTNMT chỉ có 2/22 vị trí có hàm lượng $\mathrm{Cr}$ vượt giá trị giới hạn đối với trầm tích nước ngọt là vị trí $\mathrm{SD} 1$ (vượt 1,08 lần) và vị trí $\mathrm{SD} 3$ (vượt 1,03 lần). Ngược lại, khi so sánh hàm lượng $\mathrm{Cr}$ với hướng dẫn chất lượng trầm tích tỉnh Ontario - Canada thì chỉ có 02 vị trí (SD9, SD12) có giá trị nằm dưới mức ảnh hưởng thấp (LEL) còn lại tất cả các vị trị đều vượt giá trị LEL từ 1,07 đến 3,74 lần và tiến gần đến giá trị ở mức độ có khả năng gây ảnh hưởng nghiêm trọng đến hệ thủy sinh.

So sánh với một số nghiên cứu tại Việt Nam về hàm lượng kim loại trong trầm tích, trầm tích sông Đáy có mức độ tích lũy KLN tương đối tương đồng so với trầm tích tại sông Hàn, Đà Nẵng (hàm lượng $\mathrm{Pb}: 28,2 \div 65,1 ; \mathrm{Cu}: 31,1 \div$ 76,9; Cd: $0,038 \div 0,156$; Cr: $43,7 \div 58,3 \mathrm{mg} / \mathrm{kg}$ trọng lượng khô) [9]. Trong khi đó, hàm lượng KLN trong trầm tích sông Đáy cao hơn nhiều so với hàm lượng các kim loại trong trầm tích khu vực sông Mê Kông $(\mathrm{Pb}: 0,9 \div 6,6 ; \mathrm{Cu}: 28,4 \div$ 35,7; Cd: $0,1 \div 2,4 ; \mathrm{mg} / \mathrm{kg}$ trọng lượng khô), đặc biệt là kim loại chì. Sông Soài Rạp thuộc hệ thống sông Sài Gòn - sông Đồng Nai cũng chụu ảnh hưởng bởi nhiều hoạt động công nghiệp, đặc biệt là các khu sản xuất điện tử, điện lạnh nền hàm lượng kim loại nặng trong trầm tích sông tại đây cũng khá cao, với hàm lượng $\mathrm{Pb}: 28,2 \div$ 43,9; Cu: $16,4 \div 24,7 ; \mathrm{Cr}: 307 \div 357 \mathrm{mg} / \mathrm{kg}$ trọng lượng khô [10]. Như vậy, có thể thấy, hàm lượng các kim loại trong trầm tích sông Đáy ở mức thấp so với các khu vực khác trong nước.

Kết quả hàm lượng kim loại nặng trong trầm tích sông Đáy khá tương đồng với hàm lượng kim loại nặng trong trầm tích sông Korotoa, Bangladesh (Pb: $36 \div 83$; $\mathrm{Cu}: 35 \div 118$; Cd: 0,26 $\div 2,8$; Cr: $55 \div 183 \mathrm{mg} / \mathrm{kg}$ trọng lượng khô) $[11]$ hay cửa sông Karnaphuli, Bangladesh ( $\mathrm{Pb}: 23,66$ $\div 25,05$; Cu: $20,34 \div 33,06$; Cr: 77,0 $\div$ 99,8 $\mathrm{mg} / \mathrm{kg}$ trọng lượng khô) [12]

Tuy nhiên, hàm lượng kim loại nặng trong trầm tích sông Hindon, Ân Độ $(\mathrm{Pb}: 27,56$
313,57; $\mathrm{Cu}: 21,7 \div 280,33$; Cd: $0,29 \div 6,29$ $\mathrm{mg} / \mathrm{kg}$ trọng lượng khô) cao hơn nhiều so với hàm lượng các kim loại này tại khu vực hạ lưu sông Đáy. Quá trình cồng nghiệp hóa và gia tăng dân số nhanh tại lưu vực sông Hindon là nguyên nhân gây ra sự tích lũy kim loại nặng tương đối cao trong trầm tích sông Hindon [13]. Tương tự, hàm lượng các kim loại nặng trong trầm tích sông Ganga, Ấn Độ cũng khá cao so với nghiên cứu này với $\mathrm{Pb} 148,83-211,36 ; \mathrm{Cu}: 12,67-84$; Cd: 9,52 - 79; Cr: 126,84 - 196,11 mg/kg trọng lượng khô do đây là nơi tiếp nhận các nguồn thải không được xử lý từ các hoạt động nông nghiệp, công nghiệp của khu vực [14].

\section{2. Đánh giá rủi ro sinh thái tiềm năng}

Áp dụng công thức tính từ mục 2.3 , nhóm nghiên cứu đã tiến hành tính toán yếu tố rủi ro của từng $K L N$ và hệ số rủi ro sinh thái tiềm năng. Bảng 2 thể hiện kết quả tính toán của các hệ số.

Từ kết quả trong bảng 2 kết hợp với thang đánh giá mức độ rủi ro cho thấy, yếu tố rủi ro sinh thái $\left(\mathrm{E}_{\mathrm{r}}^{\mathrm{i}}\right)$ của $\mathrm{Pb}$ dao động từ 1,13 đến 5,9 ; $\mathrm{Cu}$ từ 1,31 đến 7,$21 ; \mathrm{Cd}$ từ 5,66 , đến 72,8 và $\mathrm{Cr}$ từ 0,36 đến 2,16 . Thứ tự yếu tố rủi ro sinh thái của từng kim loại trong trầm tích được sắp xếp theo như sau: $\mathrm{E}_{\mathrm{r}}^{\mathrm{i}}(\mathrm{Cd})=29,8>\mathrm{E}_{\mathrm{r}}^{\mathrm{i}}(\mathrm{Cu})=3,97>$ $\mathrm{E}_{\mathrm{r}}^{\mathrm{i}}(\mathrm{Pb})=2,82>\mathrm{E}_{\mathrm{r}}^{\mathrm{i}}(\mathrm{Cr})=1,16$. Có thể thấy, $\mathrm{Cd}$ là yếu tố rủi ro sinh thái chính trong tổng số bốn kim loại nghiên cứu. Như vậy, theo phương pháp đánh giá rủi ro sinh thái của Hakanson thì các kim loại $\mathrm{Pb}, \mathrm{Cu}, \mathrm{Cd}, \mathrm{Cr}$ đều có mức độ rủi ro sinh thái thấp trong nghiên cứu này.

Ở Việt Nam, chưa có nhiều nghiên cứu đánh giá về mức độ rủi ro sinh thái của kim loại nặng trong trầm tích các sông. Trước nghiên cứu này, nhóm nghiên cứu cũng đã tiến hành đánh giá rủi sinh thái tại khu vực cửa sông, ven biển sông Hàn, thành phố Đà Nẵng. Kết quả các chỉ số rủi ro sinh thái của các kim loại đều thấp hơn so với nghiên cứu này, cụ thể yếu tố rủi ro sinh thái của $\mathrm{Cu}, \mathrm{Cd}, \mathrm{Pb}, \mathrm{Cr}$ lần lượt là $2,01,0,560,1,74$ và 0,660 [9]. Do đặc tính tích lũy và nguồn thải khác nhau nên mức độ tích lũy và rủi ro tại các khu vực sẽ có sự khác nhau. 
Bảng 2. Chỉ số rủi ro sinh thái kim loại nặng trong trầm tích

\begin{tabular}{|c|c|c|c|c|c|c|}
\hline \multirow{2}{*}{$\mathrm{TT}$} & \multirow{2}{*}{ Kí hiệu } & \multicolumn{4}{|l|}{$\mathrm{E}_{\mathrm{r}}^{\mathrm{i}}$} & \multirow{2}{*}{ RI } \\
\hline & & $\mathrm{Pb}$ & $\mathrm{Cu}$ & $\mathrm{Cd}$ & $\mathrm{Cr}$ & \\
\hline 1 & SD1 & 1,50 & 4,63 & 30,3 & 2,16 & 38,6 \\
\hline 2 & SD2 & 1,45 & 3,93 & 22,2 & 1,17 & 28,8 \\
\hline 3 & SD3 & 1,65 & 6,01 & 36,8 & 2,05 & 46,5 \\
\hline 4 & SD4 & 1,13 & 2,88 & 21,9 & 0,621 & 26,6 \\
\hline 5 & SD5 & 2,82 & 4,09 & 32,3 & 1,17 & 40,4 \\
\hline 6 & SD6 & 1,44 & 3,80 & 32,2 & 1,65 & 39,0 \\
\hline 7 & SD7 & 1,48 & 3,72 & 43,1 & 1,72 & 50,1 \\
\hline 8 & SD8 & 2,52 & 1,78 & 72,8 & 1,52 & 78,7 \\
\hline 9 & SD9 & 4,07 & 4,42 & 42,7 & 0,358 & 51,5 \\
\hline 10 & SD10 & 1,46 & 1,61 & 26,9 & 0,898 & 30,9 \\
\hline 11 & SD11 & 2,41 & 2,56 & 32,9 & 1,14 & 39,0 \\
\hline 12 & SD12 & 1,23 & 3,92 & 29,8 & 0,547 & 35,6 \\
\hline 13 & SD13 & 5,14 & 5,69 & 41,7 & 1,28 & 53,8 \\
\hline 14 & SD14 & 4,09 & 3,63 & 31,9 & 0,960 & 40,6 \\
\hline 15 & SD15 & 4,43 & 3,91 & 42,3 & 1,04 & 51,6 \\
\hline 16 & SD16 & 5,90 & 7,21 & 32,7 & 1,53 & 47,3 \\
\hline 17 & SD17 & 5,09 & 5,05 & 32,5 & 1,16 & 43,8 \\
\hline 18 & SD18 & 2,88 & 4,95 & 9,22 & 0,98 & 18,0 \\
\hline 19 & SD19 & 2,36 & 4,02 & 5,66 & 1,15 & 13,2 \\
\hline 20 & SD20 & 5,12 & 6,66 & 17,3 & 1,23 & 30,4 \\
\hline 21 & SD21 & 1,88 & 1,31 & 7,62 & 0,635 & 11,4 \\
\hline 22 & SD22 & 1,91 & 1,47 & 11,3 & 0,652 & 15,3 \\
\hline \multicolumn{2}{|c|}{ Trung bình } & 2,82 & 3,97 & 29,8 & 1,16 & \\
\hline
\end{tabular}

\section{Kết luận}

Hàm lượng $\mathrm{KLN}(\mathrm{Cu}, \mathrm{Pb}, \mathrm{Cd}, \mathrm{Cr})$ trong trầm tích khu vực hạ lưu sông Đáy dao động trong khoảng tương ứng là $15,8 \div 82,6 ; 13,1 \div 72,1$; $0,2 \div 2,43 ; 16,1 \div 97,3 \mathrm{mg} / \mathrm{kg}$ trọng lượng khô. Tại hầu hết các vị trí lấy mẫu, hàm lượng này đều nằm dưới giới hạn cho phép của QCVN 43:2012 về chất lượng trầm tích. Kết quả nghiên cứu này cho thấy, khu vực nghiên cứu chưa bị ô nhiễm kim loại nặng. Tuy nhiên khi đánh giá với tiêu chuẩn chất lượng trầm tích tỉnh Ontario, Canada, trầm tích sông Đáy có dấu hiệu bị ô nhiễm đối với các kim loại nghiên cứu. Kết quả đánh giá rủi ro sinh thái của các kim loại nặng trong trầm tích khu vực nghiên cứu cũng chỉ ra mức độ rủi so sinh thái thấp của tất cả các kim loại với chỉ số rủi ro sinh thái tiềm năng nằm trong khoảng từ 11,45 đến 78,66 . Trong các kim loại nghiên cứu, $\mathrm{Cd}$ là yếu tố rủi ro sinh thái chính với một số điểm có yếu tố rủi ro lên mức độ vừa phải.

Kết quả đánh giá rủi ro sinh thái tiềm năng của một số kim loại tại khu vực cho thấy mức độ rủi ro tiềm ẩn tác động đến hệ sinh thái dưới nước khi trầm tích bị ô nhiễm kim loại nặng. Trong nghiên cứu này, tuy các kim loại đều chưa bị ô nhiễm nhưng với đặc tính tích lũy kim loại của trầm tích cũng như nguy cơ rủi ro tiềm ẩn tồn tại sẽ có những tác động tiêu cực trong tương lai. Do vậy, kết quả này là cơ sở khoa học để thực hiện các biện pháp giảm thiểu các nguồn thải nội địa, quản lý tốt các nguồn nước thải từ hoạt động công nghiệp, khai khoáng và làng nghề tại lưu vực sông Nhuệ - Đáy. 


\section{Lời cảm ơn}

Nghiên cứu này được tài trợ bởi Bộ Tài nguyên và Môi trường, Đề tài cấp bộ mang mã số: TNMT 2017.04.09.

Nghiên cứu này có sự tham gia thực hiện của nghiên cứu sinh Nguyễn Khánh Linh là nghiên cứu sinh thuộc đề án 911 của Trường Đại học Khoa học Tự nhiên, Đại học Quốc gia Hà Nội.

\section{Tài liệu tham khảo}

[1] Tổng cục Môi trường (2017), Báo cáo tổng hợp kết quả quan trắc môi trường nước lưu vực sông Nhuệ - Đáy

[2] Cruz-Guzman M., Celis R., Hermosín M.C., Koskinen W.C., Nater E.A., Cornejo J. (2006), Heavy metal adsorption by Montmorillonites modified with natural organic cations. Soil Sci. Soc. Am. J. 70, (1), 215.

[3] Ding X.G., Ye S.Y., Gao Z.J. (2005), Methods of heavy metal pollution evaluation for offshore sediments, Marine Geol Lett. 21, (8), pp 31- 36.

[4] Lars Hakanson (1980), An ecological risk index for aquatic pollution control. A sedimentological approach, Water research. 14 (8), pp. 975-1001.

[5] TCVN 6663-15: 2008, Chất lượng nước - Lấy mẫu (ISO 566715: 1999) Phần 15: Hướng dẫn bảo quản và xử lý mẫu bùn và trầm tích, Bộ Khoa học và Công nghệ

[6] US - Environmental Protection Agency (1996), EPA 3050B Acid digestion of sediments, sludges and soils.

[7] F Ackermann (1980), A procedure for correcting the grain size effect in heavy metal analyses of estuarine and coastal sediment, Environmental Technology, 1(11): pp. 518-527

[8] TCVN 4080:2011 - Chất lượng đất: Phương pháp xác định độ ẩm và hệ số khô kiệt, Bộ Khoa học và Công nghệ

[9] Lê Thị Trinh (2017), Đánh giá sự tích lũy và rủi ro sinh thái một số kim loại nặng trong trầm tích cửa sông Hàn, Thành phố Đà Nẵng, Tạp chí Khoa học ĐHQGHN: Khoa học Tự nhiên và Công nghệ,. 33(3), p. 112.

[10] Nguyễn Văn Phương, Mai Hương, Nguyễn Thị Huệ (2017), Đánh giá ô nhiễm kim loại nặng $(\mathrm{Cu}$, $\mathrm{Pb}, \mathrm{Cr})$ và $\mathrm{As}$ trong trầm tích cửa sông Soài Rạp, hệ thống sông Sài Gòn - Đồng Nai, Tạp chí Môi trường - Tổng cục Môi trường

[11] Md Saiful Islam, Md Kawser Ahmed, Mohammad Raknuzzaman, Md Habibullah-Al-Mamun, Muhammad Kamrul Islam (2015), Heavy metal pollution in surface water and sediment: a preliminary assessment of an urban river in a developing country, Ecological Indicators. 48, pp. 282-291.

[12] Ai-jun Wang, Ahmed Kawser, Yong-hang Xu , Xiang Ye, Seema Rani and Ke-liang Chen (2016), Heavy metal accumulation during the last 30 years in the Karnaphuli River estuary, Chittagong, Bangladesh, Springer Plus, 5(1): p. 2079.

[13] Mayuri Chabukdhara, Arvind K Nema (2012), Assessment of heavy metal contamination in Hindon River sediments: a chemometric and geochemical approach, Chemosphere. 87(8), pp. 945-953

[14] Mayank Pandey, Smriti Tripathi, Ashutosh Kumar Pandey, and BD Tripathi, Risk assessment of metal species in sediments of the river Ganga, Catena, 2014. 122: p. 140-149. 


\title{
Heavy Metal Accumulation and Potential Ecological Risk Assessment of Surface Sediments from Day River Downstream
}

\author{
Le Thi Trinh, Kieu Thi Thu Trang, Nguyen Thanh Trung, \\ Nguyen Khanh Linh, Trinh Thi Tham
}

Hanoi University of Natural Resources \& Environment, 41A Phu Dien, Cau Dien, Hanoi, Vietnam

\begin{abstract}
According to the statistics of management agencies, the Nhue - Day river basin system is experiencing an increase in the number of polluted sources and waste water flow from production and living activities. The accumulation of persistent organic substances, heavy metals, etc., in sediments affects the quality of river water and the aquatic living system. In this study, the accumulation of heavy metals in sediments from the Day River downstream was assessed based on potential ecological risk index. Results of the research, All heavy metals were detected in sediment samples with mean concentrations of $\mathrm{Cu}, \mathrm{Pb}, \mathrm{Cd}$ and $\mathrm{Cr}$ were range of $15.8 \div 82,6 ; 13.1 \div 72.1 ; 0,189 \div 2,43 ; 16.1 \div 97.3$ $\mathrm{mg} / \mathrm{kg}$ dry weight. The potential ecological risk indexs (RI) for metals were varied from 11.4 to 78.7, show that this area has a low level of risk for heavy-metal. This data can clarify the potential risk level of the area which is the scientific basis for taking solution to control and reduce the sources of environmental pollution of the Nhue - Day river basin system.
\end{abstract}

Keywords: Heavy metal, sediment, potential ecological risk, downstream Day River. 